TI 2017-054/III

Tinbergen Institute Discussion Paper
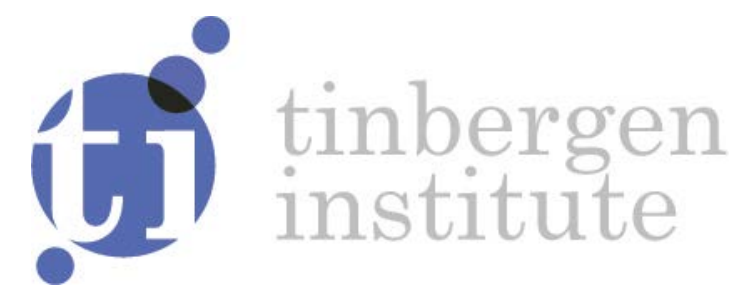

\title{
Grade expectations: rationality and overconfidence
}

Jan R. Magnus ${ }^{1}$

Anatoly A. Peresetsky ${ }^{2}$

${ }^{1}$ Vrije Universiteit Amsterdam and Tinbergen Institute, The Netherlands

${ }^{2}$ National Research University Higher School of Economics, Russia 
Tinbergen Institute is the graduate school and research institute in economics of Erasmus University Rotterdam, the University of Amsterdam and VU University Amsterdam.

Contact: discussionpapers@tinbergen.nl

More TI discussion papers can be downloaded at http://www.tinbergen.nl

Tinbergen Institute has two locations:

Tinbergen Institute Amsterdam

Gustav Mahlerplein 117

1082 MS Amsterdam

The Netherlands

Tel.: $+31(0) 205984580$

Tinbergen Institute Rotterdam

Burg. Oudlaan 50

3062 PA Rotterdam

The Netherlands

Tel.: +31(0)10408 8900 


\title{
Grade expectations: rationality and overconfidence*
}

\author{
June 11, 2017
}

Jan R. Magnus

Department of Econometrics \& Operations Research, Vrije Universiteit Amsterdam and Tinbergen Institute

Anatoly A. Peresetsky

National Research University Higher School of Economics, Moscow

${ }^{*}$ We are grateful to seminar participants at the Department of Applied Economics, Higher School of Economics, Moscow for constructive comments. E-mail addresses: jan@janmagnus.nl (Magnus), aperesetsky@hse.ru (Peresetsky). 


\title{
Corresponding author:
}

Jan R. Magnus

Department of Econometrics \& Operations Research

Vrije Universiteit Amsterdam

de Boelelaan 1105

1081 HV Amsterdam

The Netherlands

Phone: +31 205986010

E-mail: jan@janmagnus.nl

\begin{abstract}
Overconfidence seems to be an essential aspect of human nature, and one way to study overconfidence is to consider students' forecasts of their exam grades. Part of a student's grade expectation is based on the student's previous academic achievements; what remains can be interpreted as (over)confidence. In this paper we study overconfidence using a sample of about five hundred second-year undergraduate students enrolled in a statistics course in Moscow. The course contains three exams and each student produces a forecast for each of the three exams. Students' expectations are not rational and most of students are overconfident, which is in agreement with what most people find. Less obvious findings are that overconfidence is helpful: given the same academic achievement students with larger confidence get higher exam grades. Female students are less overconfident than male students, their forecasts are more rational, and they are also faster learners in the sense that they adjust their expectations more rapidly.
\end{abstract}

Keywords: Rational expectations; Classroom experiment; Overconfidence; Gender difference; Persistence. 


\section{Introduction}

People tend to overestimate their abilities. Svenson (1981), for example, estimates that $93 \%$ of US drivers and $69 \%$ of Swedish drivers consider their driving skills 'above the median'. Overconfidence appears to be one of the most robust findings in experimental psychology (De Bondt and Thaler, 1995).

The current paper is concerned with undergraduate students and how well they forecast their grade in relation to their realized grade. The first, perhaps, to investigate this issue was Murstein (1965) using a sample of 76 students from a course in educational psychology at Louisiana State University. Persistency of overconfidence was found, especially pronounced for weak students. Grimes (2002) studied a sample of 253 students composed of students enrolled in a principles of macroeconomics course at Mississippi State University. A high degree of overconfidence was found. Nowell and Alston (2007) used data from a survey conducted in 32 separate courses in economics and quantitative courses, representing every class offered by the economics department at Weber State University, Ogden, Utah, USA during one semester. The sample consists of 715 students with $70 \%$ response rate. The authors found that male students with lower grade point average (GPA) have greater overconfidence; that students in upper division classes have less of a tendency to overestimate their grade relative to students taking lower division courses; that gender matters; and that increasing the importance of tests reduces overconfidence. Hossain and Tsigaris (2015) considered students in a second year statistics for business and economics course, at Thompson Rivers University in Kamloops, British Columbia, Canada. A total of 169 students were surveyed with a response rate of over 90\%. In this paper students make several forecast of their final exam grade during the course. Rational expectations are rejected. Expectations move closer to the realized grade as students receive new information on their actual performance closer to the exam. Many other papers reject the hypothesis of rational expectations and confirm student grade overconfidence; see Kruger and Dunning (1999), Svanum and Bigatti (2006), Andrews et al. (2007), Burns (2007), Jensen and Moore (2008), Khachikian et al. (2011), Hossain and Tsigaris (2013), Foster et al. (2016), Serra and DeMarree (2016), and Sturges et al. (2016).

Is overconfidence helpful or harmful for the student? There is no consensus. Overconfidence may lead to a student allocating less time to study, resulting in poor exams grades. On the other hand, Ballard and Johnson (2005) argue that expectations could become self-fulfilling, possibly because the student with higher expectations will work harder and more intense on the course. They found that expected grades relate positively to a student's 
performance in class. Johnson and Fowler (2011) argue, along similar lines, that overconfidence may increase ambitions, morale, resolve, persistence, and thus actually increase the probability of success.

Does overconfidence depend on gender? Are women better forecasters? Again, there is now consensus. Guzman (2012) demonstrated that in the housing market gender is a significant factor in home price expectations. Women have less optimistic expectations about housing prices than man. Also, women tend to be better forecasters of unemployment and inflation than men, also when one controls for income, education, race, age, marital status, number of children in the household, et cetera. Lundeberg et al. (1994) concluded from a sample consisting of three psychology courses containing 70 men and 181 women that both men and women tend to be overconfident, but men more so, especially when they are wrong! Nowell and Alston (2007) analyzed a sample of students enrolled in economics and quantitative courses. They come to conclusion that men were $9 \%$ more likely to overestimate their grade than were women. Jakobsson (2012) also found a gender difference in the prediction error of exam grades (98 students, aged 18-35) taking the exam in introductory macroeconomics at Karlstad University, Sweden. Others do not find significant differences in prediction accuracy between men and women. Maxwell and Lopus (1994) find that both men and women tend to overstate their grade point average, but they do not find a difference by gender. Grimes (2002) and Andrews et al. (2007) also do not find gender differences in the forecast error. To the best of our knowledge, there is only one paper which states the opposite: Sharma and Shakeel (2015) study students in India and found that more of the male students seemed to be modest in the prediction of exam grades relative to the female students.

How persistent are overly optimistic expectations? Do students adjust their forecasts? Murstein (1965) found persistency of overconfidence, especially pronounced for weak students. The vast majority of the strong students showed no significant change in their predictions as their grade experience accumulated. They believed that they deserved high grades and they received high grades. The weak students did not change their predictions either, although they should have. In a sample of 60 students from a course in research methods at the Department of Psychological Sciences, Texas Tech University, Serra and DeMarree (2016) concluded that students' predictions of their grades are persistently overconfident because their predictions are biased by their desired level of performance. Foster et al. (2016) experimented with 13 consecutive (weekly) exams in an introduction to educational psychology course. They also found that students do not adjust their expectations. Grimes (2002) and Burns (2007) concluded that students grade expectations became more accurate as students gain experience in the 
course. Grimes (2002) noted that the women appeared to be more successful in revising their expectations into line with their performance than were the men.

In our study we hope to contribute to each of the questions raised above We analyze students enrolled in a second-year undergraduate course in statistics at ICEF, Moscow, in total 592 students. During the course the students take three exams and at each exam they forecast their grade. We address the following research questions: Are students' expectations rational? Are they overconfident? If so, is the level of overconfidence the same for male and female students? Is overconfidence helpful? Do students adjust their exam grades during the course when more information becomes available? And, if so, does the speed of adjustment depend on gender?

We find that, in general, students are overconfident especially male students; overconfidence is helpful; students adjust their forecasts with their experience of the course; and female students adjust their beliefs faster than male students.

The paper is organized as follows. The setup is described in Section 2. Rationality is investigated in Section 3, overconfidence in Section 4, and persistence in Section 5. Section 6 offers some concluding remarks.

\section{The experiment}

\subsection{Course organization and grading}

The International College of Economics and Finance (ICEF) in Moscow was established in 1997 jointly by the London School of Economics and Political Science (LSE) in London and the Higher School of Economics (HSE) in Moscow. The college offers a four-year bachelor's program, which is considered to be one the top programs in economics in Russia. Each year about 200 students enter the program, typically immediately after high school. In their first year the students follow, among other subjects, a course called Statistics-1, and in their second year they follow Statistics-2. Both courses are compulsory. Our data are obtained from students following Statistics-2 over a five-year period, 2011-2015. In total, 964 students took this course during these five years.

In Statistics-2 students take three exams every year, at the end of October (exam 1), the end of December (exam 2), and the end of March (exam 3). The exams are written exams, not multiple choice, and each consists of two parts ( 80 minutes each) with a ten minute break between the two parts. The level of the exam questions is the same in the two parts. In order to avoid 
cheating students are not allowed to leave and come back during each part of the exam. At the end of part 1 and at the end of the exam the examiner collects each student's work. Each part is graded out of 50 points.

In addition, students have weekly homework assignments although these are not compulsory. All handed-in assignments are graded (out of 100). The variable $H W$ denotes for each student the sum of all assignments' grades divided by the total number of assignments. For example, if a student hands in 20 of the 25 assignments and scores 100 (the maximum) for each, then $H W=(20 \times 100) / 25=80$.

After completion of the three course exams, students take two additional exams (some only take one) in early May administered by the University of London, called $S T A T_{1}$ and $S T A T_{2}$. These, like the other exams, are also graded with a maximum score of 100 . The final grade $G_{t o t}$ for the course is then determined as

$$
G_{\text {tot }}=0.14 H W+0.14 G_{1}+0.14 G_{2}+0.21 G_{3}+0.37 \max \left(S T A T_{1}, S T A T_{2}\right),
$$

where $G_{j}$ is the grade obtained in exam $j$.

Students fail if $G_{t o t}$ is smaller than some threshold to be determined by the teacher, but lying between 32 and 37 . Student also fail if $G_{3}$, the grade in the third exam, is $<25$. Exam 3 thus plays a special role in two ways: its weight is higher than the other two exams and there is a threshold grade of 25 .

\subsection{Self assessment}

At the end of the first part of each of the three exams each student is asked to forecast (out of 100) his/her grade for this exam (the two parts together). At the moment when the student writes down the forecast he/she knows the questions and his/her answers in part 1, but the student does not yet know the questions of part 2. To encourage students to fill in their forecast and to actually try their best, a bonus is promised. If the difference between the forecast and the grade is less than or equal to 3 in absolute value, then one bonus point is added to the grade. For example, if the forecast is 49 and the grade is 52, than the grade for this exam is marked up to 53. This procedure had to be and has been approved by ICEF. As a result of the procedure and the possibility of a bonus, the response rate was extremely high $(97 \%)$. The idea of giving each student an incentive to express his/her opinion was also used in a recent experiment by Blackwell (2010), where students are asked to assess the difficulty of an assignment by guessing the class average, earning a bonus if their guess is close enough. 
Smart (or risk averse) students utilize this bonus in the third exam, where the grade must be $\geq 25$. If the student chooses the forecast $F_{3}$ such that $21 \leq$ $F_{3} \leq 27$, then a grade $G_{3}=24$ would be marked up to 25 . Some students actually do this, but they then typically choose $F_{3}=24$ or 25 and not, say, 21 or 27 . The special role of the third exam and the overrepresentation of 24 and 25 in the sample of third exam forecasts has to be taken into account when we do our statistical analysis, and we shall discuss this issue further below.

\subsection{The data}

The data consist of the grades $G_{j}$ and the forecasts $F_{j}$ for $j=1,2,3$ for each of our students, and our interest is focussed on the excess expectation in exam $j$ :

$$
D_{j}=F_{j}-G_{j}
$$

We have some background knowledge on each student, namely the grades of the first-year calculus (calc) and first-year statistics (stats) exams, the grade point average at the end of the first year $(g p a)$, and whether the student is male or female (female $=1$ for women and 0 for men). We also know in which year the exam took place (year $=2011,2012,2013,2014,2015)$.

For the homework assignments we know for each student how many assignments the student handed in $\left(n h w_{j}\right)$, the sum of the grades per exam period $\left(s h w_{j}\right)$, and the number of handed-out assignments $\left(n h w m a x_{j}\right)$. The index $j$ now refers to a period rather than to a point in time: $j=1$ refers to the period up to the first exam, $j=2$ to the period between the first and second exams, and $j=3$ to the period between the second and third exams. The number of handed-out assignments $\left(\right.$ nhwmax $\left._{j}\right)$ may vary from year to year, in fact from 4-7 in period 1 , from 6-7 in period 2 , and from 9-12 in period 3 .

From these 'raw' data we can compute the ratios

$$
r n h w_{j}=n h w_{j} / n h w m a x_{j}, \quad r s h w_{j}=s h w_{j} / n h w_{j},
$$

which denote, respectively, the relative number of submitted assignments for each student in period $j\left(0 \leq r n h w_{j} \leq 1\right)$, and the average submitted assignment grade for each student in period $j\left(0 \leq r s h w_{j} \leq 100\right)$, where we set $r s h w_{j}=0$ if $n h w_{j}=0$. These ratios will be used later in the analysis.

In order to obtain a clean and complete sample, some data screening was necessary. Of the original 964 students we excluded those students who (a) did not take all three exams; or (b) had repeated the first year; or (c) had 
failed the course last year; or (d) had taken a break between the first and second year. This left us with 840 students.

Of these 840 students, a further 248 were excluded because they did not provide all three forecasts or we didn't have their first-year results. As a consequence, 592 students remain on which we have complete information. The results of the University of London exams are not used in our analysis.

Table 1: Basic data, averaged

\begin{tabular}{llccccc}
\hline & 2011 & 2012 & 2013 & 2014 & 2015 & All \\
\hline$G_{1}$ & 40.81 & 33.87 & 33.94 & 40.18 & 28.13 & 35.30 \\
$G_{2}$ & 48.41 & 34.49 & 47.50 & 27.35 & 32.70 & 36.90 \\
$G_{3}$ & 47.77 & 41.41 & 39.00 & 38.16 & 38.55 & 40.27 \\
$F_{1}$ & 36.49 & 43.04 & 39.06 & 34.68 & 38.93 & 38.21 \\
$F_{2}$ & 48.82 & 42.85 & 40.54 & 38.06 & 38.58 & 40.98 \\
$F_{3}$ & 48.49 & 37.86 & 41.69 & 38.00 & 37.41 & 40.06 \\
\hline Observations & 79 & 103 & 129 & 158 & 123 & 592 \\
female (\%) & 40.51 & 36.89 & 41.09 & 39.87 & 47.15 & 41.22 \\
\hline
\end{tabular}

A summary of the data is provided in Table 1 . There is substantial variation in the exam grades $G$ and the forecasts $F$ over the years, possibly because the difficulty of the exams varies (although the same instructor taught the course over this period) or the quality of the student population varies (because of changes in admission policies). This suggests that year dummies may be important. On the whole it seems that students are too optimistic about their abilities, because $F_{j}>G_{j}$ occurs more frequently than $F_{j}<G_{j}$. Also, in the first two exams large deviations occur where $\left|F_{j}-G_{j}\right|$ can be larger than 10, in contrast to the third exam where the deviation is much smaller. This suggests that students learn from their past forecast errors. All these issues will be discussed more fully in the following sections.

\section{Rationality}

Our first question is whether our students have rational expectations about their exam grades. In the Introduction we mentioned some literature where it is found that students overestimate their abilities, that is, that they are not rational. If we also find this (as we shall) then a second question arises, namely whether male and female students are equally irrational or that perhaps female students behave more rationally than male students.

Our experimental data differ from the data in most papers in three respects: first, we use a 0-100 grade system, while other papers typically use 
the more discrete F-D-C-B-A (0-4) grade system; second, our students make their forecast after they have already finished half the exam; and third, our students have a real incentive to make their forecast as precise as possible, as they get a bonus for an accurate forecast.

There is, in addition, one other feature of our data, namely the fact that we collected exam results and the associated forecasts during five years (2011-2015). We know from the previous section that the exams are not equally difficult in each year, and these discrepancies need to be taken into account. Thus, following Hossain and Tsigaris (2015), we regress the excess expectation $D_{j, i}=F_{j, i}-G_{j, i}$ for student $i$ in exam $j$ for each of the three exams separately, and include year dummies year ${ }_{i}^{(12)}-$ year $_{i}^{(15)}$. The regression then reads

$$
D_{j, i}=\alpha_{j}+x_{j, i}^{\prime} \beta_{j}+\operatorname{year}_{i}^{\prime} \gamma_{j}+\text { female }_{i} \delta_{j}+\epsilon_{j, i},
$$

where $x_{j, i}$ is the vector of all available information at the time of exam $j$ of the $i$-th student's previous academic achievements, and the control variables are a vector of time dummies

$$
\text { year }_{i}=\left(\text { year }_{i}^{(12)}, \text { year }_{i}^{(13)}, \text { year }_{i}^{(14)}, \text { year }_{i}^{(15)}\right)^{\prime},
$$

and the female/male dummy female ${ }_{i}$. The $\alpha_{j}, \beta_{j}, \gamma_{j}$, and $\delta_{j}$ are unknown parameters (parameter vectors), and $\epsilon_{j, i}$ is the random error, which we assume to be independently and identically distributed with mean zero.

We define a student to be rational when the conditional expectation $\mathrm{E}\left(D_{j, i} \mid x_{j, i}\right)=0$ and this translates to testing the null hypothesis

$$
\mathrm{H}_{0}: \beta_{j}=0
$$

for each of the three exams $j=1,2,3$. Note that the dimension of $\beta_{j}$ is not the same for each $j$, because more information is available at the second exam than at the first exam, and even more information is available at the third exam. In fact, the dimension is 5 at the first exam (calc, stats, gpa, $\left.r n h w_{1}, r s h w_{1}\right), 8$ at the second (the previous plus $G_{1}, r n h w_{2}, r s h w_{2}$ ), and 11 at the third (the previous plus $G_{2}, r n h w_{3}, r s h w_{3}$ ).

Recall that the third exam is special because students fail the course when $G_{3}<25$. From the student's point of view it makes good sense to predict $21 \leq F_{3} \leq 27$, because then (and only then) a grade $G_{3}=24$ will be marked up to 25. This is 'rational' behavior, but not according to our definition. In practice, these students choose $G_{3}=24$ or 25 , but almost never 26 or 27 . Also, some students are confused and believe that this rule applies to all three exams and not only to the third. To avoid these problems we only include forecasts which satisfy $F_{j, i}>25$. 
Table 2 contains the regression results for each of the three exams separately. The last row in the table contains the $p$-value of the $F$-test used for testing the hypothesis that $\beta_{j}=0$. The reported $p$-values are less than $0.2 \%$ thus rationality is firmly rejected in this model. The $p$-value is lowest at the first exam, still very low at the second (where more information is available), and much higher (but still less that $0.2 \%$ ) at the third (where even more information is available). More information thus leads to more rational decisions, which is not as obvious as may seem. Too much information might easily turn into confusion and lead to less rational behavior, but this does not happen here.

Some preliminary conclusions can be drawn from Table 2. First, it seems that good students (high marks in calc, stats, and gpa in the previous year) are more cautious than not so good students in their predictions, at least for the first exam. If the student does well in the first exam, then he/she becomes less cautious and in fact tends to overpredict the results of both the second and the third exam. Having learnt their lesson, students become more cautious again: doing well in the second exam leads to more rather than to less caution in predicting their mark for the third exam. Their is a big impact of gender. Women are more cautious than men in all three exams, although the impact diminishes over time.

To further investigate the difference in rationality between women and men, we also estimate the extended model

$$
D_{j, i}=\alpha_{j}+x_{j, i}^{\prime} \beta_{j}+\operatorname{year}_{i}^{\prime} \gamma_{j}+\epsilon_{j, i}
$$

for men and women separately, thus excluding the female dummy. The results are presented in Table 3, where we have again excluded all students with $F_{j, i} \leq 25$.

By including the female dummy (as in Table 2) we distinguish between men and women, but only by allowing the level to change from $\alpha_{j}$ for men to $\alpha_{j}+\delta_{j}$ for women. By separating men and women (as in Table 3 ) we also allow the $\beta_{j}$-coefficients to be different.

Our preliminary conclusions still hold in this extended framework. Women are more cautious than men. Good students are more cautious than not so good students in their predictions, at least for the first exam. If the student does well in the first exam, then he/she becomes too optimistic in predicting the second exam, but doing well in the second exam does not lead to such optimism. The $p$-values are higher than in Table 2 but still well under $0.1 \%$, except for women in the third exam where the $p$-value is close to $5 \%$. We thus find that our female students became more rational in the third exam, while men continue to exhibit irrational behavior. 
It is often thought that women behave more rationally than men, and this is indeed what we find. But there is no consensus in the literature. Ballard and Johnson (2005) report that gender is a significant determinant of student expectations: women in an introductory microeconomics course expected a grade that was one-fourth of a letter grade ( 0.25 on a 4.0 scale) lower than the grade expected by the men. However, after controlling for expectations and secondary-schooling experience with economics, the gender effect became small and insignificant. Hossain and Tsigaris (2015) too find that gender makes no difference in this respect. 
Table 2: Rationality, $F_{j}>25$

\begin{tabular}{|c|c|c|c|}
\hline & $D_{1}$ & $D_{2}$ & $D_{3}$ \\
\hline \multirow[t]{2}{*}{ calc } & -0.106 & -0.110 & 0.138 \\
\hline & $(0.097)$ & $(0.093)$ & $(0.097)$ \\
\hline \multirow[t]{2}{*}{ stats } & -0.159 & $-0.247^{* *}$ & -0.119 \\
\hline & $(0.137)$ & $(0.118)$ & $(0.133)$ \\
\hline \multirow{2}{*}{ gpa } & -0.155 & 0.143 & -0.086 \\
\hline & $(0.163)$ & $(0.141)$ & $(0.153)$ \\
\hline \multirow[t]{2}{*}{$r n h w_{1}$} & -0.773 & -0.515 & 1.811 \\
\hline & $(3.028)$ & $(3.335)$ & $(3.690)$ \\
\hline \multirow[t]{2}{*}{$r s h w_{1}$} & -0.055 & -0.031 & $0.086^{*}$ \\
\hline & $(0.041)$ & $(0.039)$ & $(0.045)$ \\
\hline \multirow[t]{2}{*}{$G_{1}$} & & $0.121^{* *}$ & $0.141^{* *}$ \\
\hline & & $(0.054)$ & $(0.058)$ \\
\hline$r n h w_{2}$ & & $\begin{array}{c}-8.071^{* *} \\
(3.203)\end{array}$ & $\begin{array}{c}-0.747 \\
(3.929)\end{array}$ \\
\hline \multirow[t]{2}{*}{$r \operatorname{sh} w_{2}$} & & -0.032 & 0.002 \\
\hline & & $(0.041)$ & $(0.049)$ \\
\hline \multirow[t]{2}{*}{$G_{2}$} & & & $-0.162^{* * *}$ \\
\hline & & & $(0.060)$ \\
\hline \multirow[t]{2}{*}{$r n h w_{3}$} & & & -5.741 \\
\hline & & & $(3.486)$ \\
\hline \multirow[t]{2}{*}{$r s h w_{3}$} & & & -0.037 \\
\hline & & & $(0.046)$ \\
\hline \multirow[t]{2}{*}{ female } & $-4.913^{* * *}$ & $-3.060^{* *}$ & $-2.373^{*}$ \\
\hline & $(1.381)$ & $(1.224)$ & $(1.293)$ \\
\hline \multirow[t]{2}{*}{ constant } & $31.52^{* * *}$ & $18.22^{* * *}$ & $8.65^{*}$ \\
\hline & $(4.71)$ & $(4.21)$ & $(4.69)$ \\
\hline Observations & 414 & 458 & 393 \\
\hline$R^{2}$ & 0.326 & 0.296 & 0.126 \\
\hline$R_{a d j}^{2}$ & 0.309 & 0.275 & 0.088 \\
\hline RMSE & 13.50 & 12.48 & 12.10 \\
\hline$p$-val ( $F$-test $)$ & 0 & $1.9 \cdot 10^{-7}$ & 0.0011 \\
\hline
\end{tabular}

Standard errors in parentheses.

${ }^{* * *} p<0.01,{ }^{* *} p<0.05,{ }^{*} p<0.10$. 
Table 3: Rationality, men versus women, $F_{j}>25$

\begin{tabular}{|c|c|c|c|c|c|c|}
\hline & \multicolumn{3}{|c|}{ Men } & \multicolumn{3}{|c|}{ Women } \\
\hline & $\overline{D_{1}}$ & $D_{2}$ & $\overline{D_{3}}$ & $\overline{D_{1}}$ & $D_{2}$ & $D_{3}$ \\
\hline \multirow[t]{2}{*}{ calc } & -0.152 & -0.114 & 0.032 & -0.087 & -0.089 & 0.222 \\
\hline & $(0.135)$ & $(0.128)$ & $(0.129)$ & $(0.142)$ & $(0.139)$ & $(0.157)$ \\
\hline \multirow[t]{2}{*}{ stats } & -0.084 & -0.265 & -0.230 & -0.277 & -0.239 & -0.062 \\
\hline & $(0.194)$ & $(0.160)$ & $(0.171)$ & $(0.189)$ & $(0.176)$ & $(0.224)$ \\
\hline \multirow[t]{2}{*}{ gpa } & -0.092 & 0.282 & 0.166 & -0.222 & -0.028 & -0.308 \\
\hline & $(0.232)$ & $(0.193)$ & (0.197) & $(0.224)$ & $(0.210)$ & $(0.254)$ \\
\hline \multirow[t]{2}{*}{$r n h w_{1}$} & -1.473 & 0.392 & 6.139 & 2.447 & -2.430 & -6.787 \\
\hline & $(4.111)$ & $(4.285)$ & $(4.482)$ & $(4.716)$ & $(5.800)$ & $(6.827)$ \\
\hline \multirow[t]{2}{*}{$r s h w_{1}$} & -0.071 & -0.033 & 0.017 & -0.035 & -0.023 & $0.147^{* *}$ \\
\hline & $(0.058)$ & $(0.053)$ & $(0.059)$ & $(0.057)$ & $(0.059)$ & $(0.070)$ \\
\hline \multirow{2}{*}{$G_{1}$} & & 0.052 & $0.214^{* * *}$ & & $0.207^{* *}$ & 0.047 \\
\hline & & $(0.075)$ & $(0.078)$ & & $(0.081)$ & $(0.095)$ \\
\hline \multirow[t]{2}{*}{$r n h w_{2}$} & & $-9.627^{* *}$ & -1.213 & & -5.095 & 4.109 \\
\hline & & $(4.104)$ & $(4.831)$ & & $(5.467)$ & $(7.193)$ \\
\hline \multirow[t]{2}{*}{$r s h w_{2}$} & & 0.006 & 0.052 & & -0.090 & -0.106 \\
\hline & & $(0.053)$ & $(0.060)$ & & $(0.066)$ & $(0.091)$ \\
\hline \multirow[t]{2}{*}{$G_{2}$} & & & $-0.240^{* * *}$ & & & -0.001 \\
\hline & & & $(0.074)$ & & & $(0.108)$ \\
\hline \multirow[t]{2}{*}{$r n h w_{3}$} & & & $-10.776^{* *}$ & & & 0.281 \\
\hline & & & $(4.419)$ & & & $(5.826)$ \\
\hline \multirow[t]{2}{*}{$r s h w_{3}$} & & & 0.019 & & & -0.102 \\
\hline & & & (0.058) & & & $(0.083)$ \\
\hline \multirow[t]{2}{*}{ constant } & $28.38^{* * *}$ & $11.40^{* *}$ & 3.48 & $30.83^{* * *}$ & $23.76^{* * *}$ & $16.26^{* *}$ \\
\hline & $(6.75)$ & $(5.79)$ & $(6.15)$ & $(6.62)$ & $(6.32)$ & $(7.46)$ \\
\hline Observations & 244 & 268 & 234 & 170 & 190 & 159 \\
\hline$R^{2}$ & 0.251 & 0.302 & 0.140 & 0.418 & 0.301 & 0.164 \\
\hline$R_{a d j}^{2}$ & 0.222 & 0.269 & 0.081 & 0.386 & 0.253 & 0.076 \\
\hline RMSE & 14.62 & 13.21 & 12.14 & 11.85 & 11.41 & 11.99 \\
\hline$p$-val $(F$-test $)$ & $3.6 \cdot 10^{-5}$ & 0.0060 & 0.0060 & $1.4 \cdot 10^{-7}$ & 0.0002 & 0.0434 \\
\hline
\end{tabular}

Standard errors in parentheses.

*** $p<0.01,{ }^{* *} p<0.05,{ }^{*} p<0.10$. 


\section{Overconfidence}

In the previous section we rejected rationality in predicting exam results and we saw that there is a difference between male and female students. Our next step is to try and explain this lack of rationality, and our hypothesis is that students (especially male students) are too confident about their abilities. When a student has more confidence than is justified by his or her grades, we call this student 'overconfident'.

It makes sense that a student who does well in exams gains in confidence. But perhaps the opposite is also true, that is, a confident student - other things being equal - performs better than one lacking in confidence (Ballard and Johnson, 2005; Johnson and Fowler, 2011). In addition to studying overconfidence we also try to answer this somewhat subtler question in the current section.

An overconfident student will produce a forecast which is higher than can be explained by previous academic results. We write the forecast as

$$
F_{j, i}=\alpha_{j}+x_{j, i}^{\prime} \beta_{j}+\operatorname{year}_{i}^{\prime} \gamma_{j}+\epsilon_{j, i}
$$

which is the same as (3), except that the dependent variable is now the forecast $F_{j, i}$ rather than the excess expectation $D_{j, i}$ and also that the female dummy has been deleted.

The reason for not including the female dummy is that we think of the forecast as a combination of two effects: a part based on factual information and a remainder which we identify with overconfidence. This overconfidence will depend on other things, one of which may be gender. We don't observe the remainder (the errors $\epsilon_{j, i}$ ), but we can predict it through the residuals

$$
\operatorname{conf}_{j, i}=F_{j, i}-\hat{\alpha}_{j}-x_{j, i}^{\prime} \hat{\beta}_{j}-\operatorname{year}_{i}^{\prime} \hat{\gamma}_{j},
$$

where $\hat{\alpha}_{j}, \hat{\beta}_{j}$, and $\hat{\gamma}_{j}$ are the least-squares estimates from (5). These residuals thus capture that part of the student's forecast which cannot be explained rationally, and thus correspond to our idea of (over)confidence, which is why we denote them by $\operatorname{conf}_{j, i}$. Note that if we would include the female dummy in (5) then conf and female would be orthogonal to each other, and this is not reasonable.

Overconfidence, thus defined, may include some information which is not available to us, such as private lessons taken before the exam or certain psychological features of the student. Since this information is not available to us we ignore it.

In the first step of the estimation procedure we thus estimate $F_{j, i}$ and obtain the residuals $\operatorname{conf}_{j, i}$. In the second step we regress the exam grades 
$G_{j, i}$ on the same set of regressors as in (5) and, in addition, on the residuals $\operatorname{conf}_{j, i}$ and the female dummy (and a cross term):

$$
\begin{aligned}
G_{j, i}= & \alpha_{j}+x_{j, i}^{\prime} \beta_{j}+\operatorname{year}_{i}^{\prime} \gamma_{j}+\text { female }_{i} \delta_{j} \\
& +\operatorname{conf}_{j, i} \phi_{j}+\text { female }_{i} \times \operatorname{conf}_{j, i} \psi_{j}+\epsilon_{j, i}
\end{aligned}
$$

The results of the two-step procedure are presented in Table 4 . The left panel $\left(F_{1}, F_{2}, F_{3}\right)$ gives the results of the first step. We see that first-year calculus and (to a lesser extent) statistics are important for $F_{1}$, but that home assignments are not important for the forecast. For $F_{2}$, the result $G_{1}$ of the first exam is important, while first-year calculus remains important as well. For the final exam the forecast $F_{3}$ depends much on the results of the earlier two exams $G_{1}$ and $G_{2}$. The results of first-year calculus (and statistics) are not important any more; these are absorbed in the grades $G_{1}$ and $G_{2}$, because recent information is more relevant than older information. We note that $R_{a d j}^{2}$ increases with the exam number, suggesting that with each exam students become more accurate in their forecasts.

The right panel $\left(G_{1}, G_{2}, G_{3}\right)$ gives the results of the second step, and allows us to test various hypotheses. We see that $\phi$ is significantly positive at the $1 \%$ significance level for all three exams. Its value increases with time/exam number $(0.225,0.282,0.345)$, so the impact of overconfidence increases. At least for men. For women the impact decreases (0.396, 0.272, $0.158)$ when we take the cross term into account. There is evidence in the literature that the more important is the exam the smaller is the overconfidence (Nowell and Alston, 2007). In our case this is true for women but not for men.

The female dummy is not significant and its cross term with conf is significant (at 5\%) only for the first exam. In contrast to the results in the left panel (the forecasts), more of the 'factual' regressors $x_{j}$ are significant in the right panel (the grades). The impact of the first-year courses (calculus, statistics, GPA) decreases during the second year, as is to be expected. The grades are significant: $G_{1}$ is significant in the $G_{2}$ regression (and somewhat less in the $G_{3}$ regression), and $G_{2}$ is significant in the $G_{3}$ regression. Homework results, while not significant for the students' forecasts, are significant for the grades, but only the most recent homework results. The reason, perhaps, is that students understand that homework results are not representative, because there is much collaboration among students and in fact some cheating, so they don't take it into account when forming their forecast. But the plain fact that a student submits the homework (whether own work or not) apparently helps to get a better grade. This finding agrees 
with Weems (1998), but not with Geide-Stevenson (2009).

Thus we conclude that (a) overconfidence helps in getting a better grade; (b) the impact of information deteriorates quickly over time; (c) homework results are important for the grades, but unimportant for the forecasts; and (d) gender is not significant in exam grades.

We next ask: does overconfidence depend on gender? To answer this question we consider the regression

$$
\operatorname{conf}_{j, i}=\alpha_{j}+\text { female }_{i} \delta_{j}+\epsilon_{j, i}
$$

where we note that conf is orthogonal to the year dummy and the available information in $x$, because conf is the vector of residuals from (5).

Table 5 shows that, given the same objective factors, male students tend to be more optimistic in forecasting their exam grades than female students. The difference ranges from approximately 2.7 to 5.0 grade points, and this difference seems to decrease over time (within one exam year). Transforming these grade points to a $0-4$ scale we divide by 25 and obtain 0.11 and 0.20 , which is of the same order as in Ballard and Johnson (2005). 
Table 4: Overconfidence results

\begin{tabular}{|c|c|c|c|c|c|c|}
\hline & \multicolumn{3}{|c|}{ First step } & \multicolumn{3}{|c|}{ Second step } \\
\hline & $F_{1}$ & $F_{2}$ & $F_{3}$ & $G_{1}$ & $G_{2}$ & $G_{3}$ \\
\hline \multirow[t]{2}{*}{ conf } & & & & $0.225^{* * *}$ & $0.282^{* * *}$ & $0.345^{* * *}$ \\
\hline & & & & $(0.050)$ & $(0.055)$ & $(0.067)$ \\
\hline \multirow[t]{2}{*}{ female } & & & & 1.329 & 0.750 & 0.204 \\
\hline & & & & (1.064) & $(0.986)$ & $(1.071)$ \\
\hline \multirow[t]{2}{*}{ female $\times$ conf } & & & & $0.171^{* *}$ & -0.010 & -0.187 \\
\hline & & & & $(0.087)$ & $(0.097)$ & $(0.116)$ \\
\hline \multirow[t]{2}{*}{ calc } & $0.443^{* * *}$ & $0.325^{* * *}$ & 0.083 & $0.529^{* * *}$ & $0.411^{* * *}$ & -0.068 \\
\hline & $(0.090)$ & $(0.078)$ & $(0.077)$ & $(0.073)$ & $(0.074)$ & $(0.079)$ \\
\hline \multirow[t]{2}{*}{ stats } & $0.223^{*}$ & -0.032 & 0.055 & $0.377^{* * *}$ & $0.218^{* *}$ & 0.178 \\
\hline & $(0.128)$ & $(0.101)$ & $(0.107)$ & $(0.103)$ & $(0.094)$ & $(0.109)$ \\
\hline \multirow[t]{2}{*}{$g p a$} & 0.080 & 0.123 & -0.046 & $0.270^{* *}$ & 0.004 & 0.060 \\
\hline & $(0.152)$ & $(0.120)$ & $(0.122)$ & $(0.122)$ & $(0.112)$ & $(0.126)$ \\
\hline \multirow[t]{2}{*}{$r n h w_{1}$} & -1.074 & -0.651 & -0.197 & 0.798 & 0.287 & -2.511 \\
\hline & $(2.818)$ & $(2.837)$ & $(2.960)$ & $(2.274)$ & $(2.657)$ & $(3.062)$ \\
\hline \multirow[t]{2}{*}{$r s h w_{1}$} & 0.019 & -0.008 & 0.058 & $0.072^{* *}$ & 0.017 & -0.030 \\
\hline & $(0.038)$ & $(0.033)$ & $(0.036)$ & $(0.031)$ & $(0.031)$ & $(0.037)$ \\
\hline \multirow[t]{2}{*}{$G_{1}$} & & $0.305^{* * *}$ & $0.268^{* * *}$ & & $0.186^{* * *}$ & $0.122^{* *}$ \\
\hline & & $(0.046)$ & $(0.047)$ & & $(0.043)$ & $(0.048)$ \\
\hline \multirow[t]{2}{*}{$r n h w_{2}$} & & -1.125 & -3.813 & & $7.416^{* * *}$ & -2.436 \\
\hline & & $(2.723)$ & $(3.150)$ & & $(2.547)$ & $(3.221)$ \\
\hline \multirow[t]{2}{*}{$r s h w_{2}$} & & 0.055 & -0.005 & & $0.088^{* * *}$ & -0.005 \\
\hline & & $(0.035)$ & $(0.039)$ & & $(0.032)$ & $(0.040)$ \\
\hline \multirow[t]{2}{*}{$G_{2}$} & & & $0.394^{* * *}$ & & & $0.550^{* * *}$ \\
\hline & & & $(0.048)$ & & & $(0.049)$ \\
\hline \multirow[t]{2}{*}{$r n h w_{3}$} & & & 1.658 & & & $7.836^{* * *}$ \\
\hline & & & $(2.797)$ & & & $(2.857)$ \\
\hline \multirow[t]{2}{*}{$r s h w_{3}$} & & & -0.012 & & & 0.020 \\
\hline & & & $(0.037)$ & & & $(0.038)$ \\
\hline \multirow[t]{2}{*}{ constant } & 7.12 & $14.79^{* * *}$ & $18.08^{* * *}$ & $-24.24^{* * *}$ & -3.25 & $10.11^{* * *}$ \\
\hline & $(4.42)$ & $(3.59)$ & $(3.77)$ & $(3.54)$ & $(3.36)$ & $(3.85)$ \\
\hline Observations & 414 & 458 & 393 & 414 & 458 & 393 \\
\hline$R^{2}$ & 0.353 & 0.525 & 0.642 & 0.719 & 0.734 & 0.682 \\
\hline$R_{a d j}^{2}$ & 0.338 & 0.512 & 0.627 & 0.710 & 0.725 & 0.667 \\
\hline RMSE & 12.67 & 10.64 & 9.72 & 10.13 & 9.92 & 9.91 \\
\hline
\end{tabular}

Standard errors in parentheses.

${ }^{* * *} p<0.01,{ }^{* *} p<0.05,{ }^{*} p<0.10$. 
Table 5: Overconfidence and gender

\begin{tabular}{lccc}
\hline & $(1)$ & $(2)$ & $(3)$ \\
\hline female & $-5.036^{* * *}$ & $-2.987^{* * *}$ & $-2.699^{* * *}$ \\
& $(1.228)$ & $(0.987)$ & $(0.971)$ \\
constant & $2.068^{* * *}$ & $1.239^{*}$ & $1.092^{*}$ \\
& $(0.787)$ & $(0.636)$ & $(0.618)$ \\
\hline Observations & 414 & 458 & 393 \\
$R^{2}$ & 0.039 & 0.020 & 0.019 \\
$R_{a d j}^{2}$ & 0.037 & 0.018 & 0.017 \\
RMSE & 12.30 & 10.41 & 9.45 \\
\hline
\end{tabular}

Standard errors in parentheses.

${ }^{* * *} p<0.01,{ }^{* *} p<0.05,{ }^{*} p<0.10$. 


\section{Persistence}

In the previous section we predicted and studied overconfidence as measured by the residuals $\operatorname{conf}_{j, i}$ for each student $i$ and exam $j$. We found that this overconfidence tends to become smaller as the year progresses. We now address this issue in more depth. That is, we ask whether overconfidence decreases, which would mean that students adjust their (over)confidence.

To answer this question we estimate the dynamic regressions

$$
\operatorname{conf}_{j, i}=\alpha_{j}+\operatorname{year}_{i}^{\prime} \gamma_{j}+\theta_{j} \operatorname{conf}_{j-1, i}+\epsilon_{j, i} . \quad(j=2,3)
$$

If $\left|\theta_{2}\right|<1$ then learning takes place between exams 1 and 2. Similarly, if $\left|\theta_{3}\right|<1$ then learning takes place between exams 2 and 3 . We run these regressions separately for men and women, because we have seen that overconfidence is not the same for men and women.

\begin{tabular}{lcc}
\multicolumn{3}{l}{ Table 6: Persistence from exam 1 to exam 2 } \\
\hline conf $_{1}$ & Men & Women \\
& $0.349^{* * *}$ & $0.185^{* * *}$ \\
& $(0.054)$ & $(0.062)$ \\
\hline year $^{(12)}$ & -1.252 & -3.063 \\
& $(2.564)$ & $(2.420)$ \\
year $^{(13)}$ & -1.956 & -1.422 \\
& $(2.542)$ & $(2.436)$ \\
year $^{(14)}$ & -1.461 & -2.097 \\
& $(2.494)$ & $(2.252)$ \\
year $^{(15)}$ & -0.922 & -3.309 \\
& $(2.578)$ & $(2.394)$ \\
\hline constant & 2.040 & 0.719 \\
& $(2.025)$ & $(1.826)$ \\
\hline Observations & 206 & 152 \\
$R^{2}$ & 0.177 & 0.076 \\
$R_{\text {adj }}^{2}$ & 0.156 & 0.045 \\
RMSE & 10.31 & 8.55 \\
\hline
\end{tabular}

Standard errors in parentheses.

${ }^{* * *} p<0.01,{ }^{* *} p<0.05,{ }^{*} p<0.10$.

The results are presented in Tables 6 and 7 . It is clear that adjustment occurs, since $\left|\theta_{j}\right|$ is significantly smaller than one. For the adjustment from exam 1 to exam 2 we find $\theta_{2}=0.19$ for women and $\theta_{2}=0.35$ for men, The difference between men and women is statistically significant. For the 
Table 7: Persistence from exam 2 to exam 3

\begin{tabular}{lcc}
\hline & Men & Women \\
\hline conf $_{2}$ & $0.351^{* * *}$ & $0.431^{* * *}$ \\
& $(0.050)$ & $(0.072)$ \\
\hline year $^{(12)}$ & -0.431 & 2.050 \\
& $(2.029)$ & $(2.275)$ \\
year $^{(13)}$ & 2.052 & -2.218 \\
& $(2.008)$ & $(2.216)$ \\
year $^{(14)}$ & 1.487 & -1.562 \\
& $(1.904)$ & $(2.086)$ \\
year $^{(15)}$ & 1.978 & -1.416 \\
& $(2.042)$ & $(2.216)$ \\
\hline constant & -0.855 & -0.322 \\
& $(1.513)$ & $(1.641)$ \\
\hline Observations & 213 & 143 \\
$R^{2}$ & 0.201 & 0.238 \\
$R_{\text {adj }}^{2}$ & 0.181 & 0.210 \\
RMSE & 8.68 & 7.87 \\
\hline
\end{tabular}

Standard errors in parentheses.

${ }^{* * *} p<0.01,{ }^{* *} p<0.05,{ }^{*} p<0.10$.

adjustment from exam 2 to exam 3 we find $\theta_{3}=0.43$ for women and $\theta_{3}=0.35$ for men, and this difference is not statistically significant.

Thus we conclude that (a) confidence adjustment occurs for both male and female students; (b) the adjustment from exam 1 to exam 2 is stronger than the adjustment from exam 2 to exam 3; (c) female students are faster learners, certainly in the step from exam 1 to exam 2; and (d) overconfidence persists (since the values of $\theta_{j}$ are all positive) and this persistency is stronger for men than for women.

We can go one step further. In the above regressions we estimated the average values of the adjustment coefficient for male and female students. But each student is different and this coefficient may vary from student to student. In order to estimate the individual values of the adjustment coefficient we model $\theta_{j}$ as a function of the individual characteristics of a student:

$$
\theta_{j, i}=\theta_{0, j}+x_{j, i}^{\prime} \theta_{1, j} \quad(j=2,3) .
$$

Inserting (10) in (9) then gives

$$
\operatorname{conf}_{j, i}=\alpha_{j}+\operatorname{year}_{i}^{\prime} \gamma_{j}+\theta_{j, i} \operatorname{conf}_{j-1, i}+\epsilon_{j, i} \quad(j=2,3) .
$$


Instead of estimates $\hat{\theta}_{j}$ we now obtain distributions (over $i$ ) of estimates $\hat{\theta}_{j, i}=\hat{\theta}_{0, j}+x_{j, i}^{\prime} \hat{\theta}_{1, j}$.

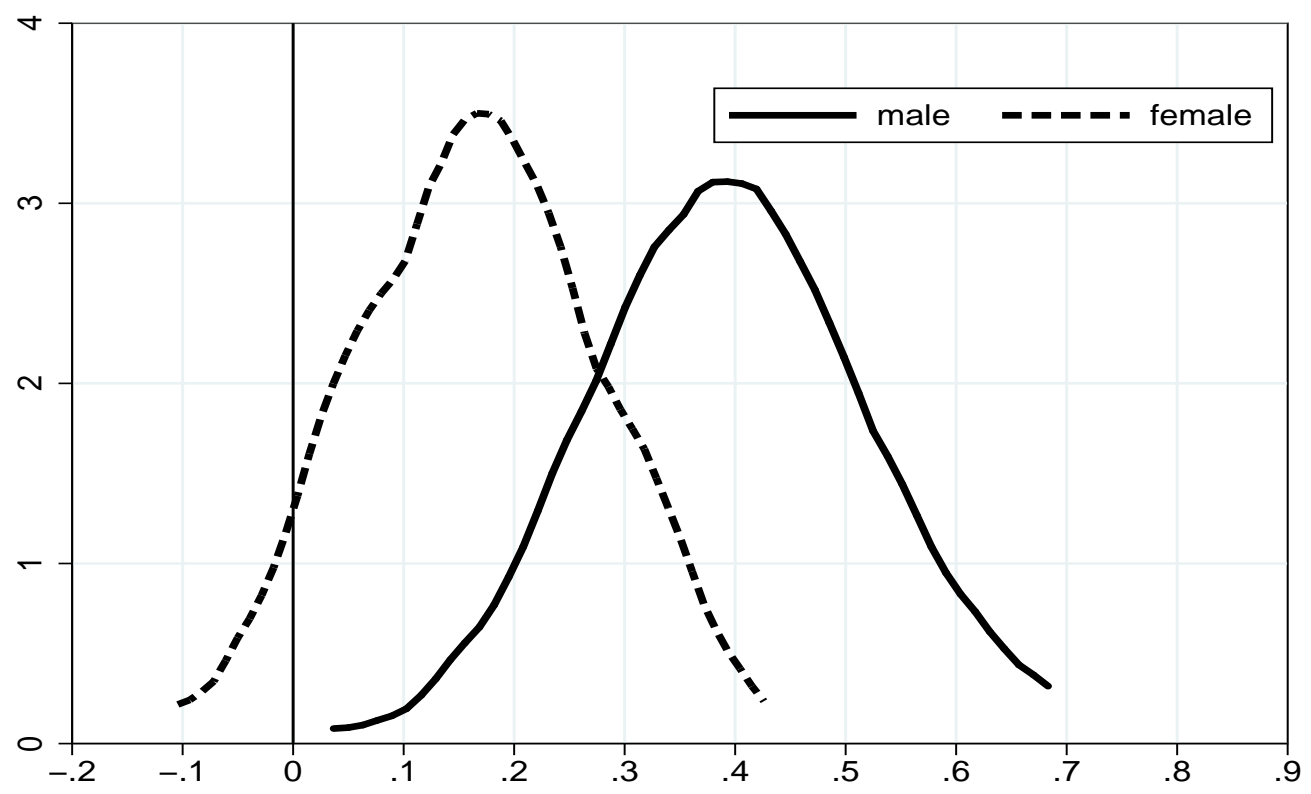

Figure 1: Persistence from exam 1 to exam 2

Kernel density plots for the distribution of the adjustment coefficient are presented in Figure 1 for the adjustment from exam 1 to exam 2) and Figure 2 for the adjustment from exam 2 to exam 3 ). We see from the first figure that the density plot for women is shifted towards zero, again demonstrating that female students are faster learners (lower persistence) than male students. There is no significant difference between the density plots for the adjustment from exam 2 to exam 3.

The figures provide further (and more detailed) confirmation of our previous conclusions, namely that (a) adjustment takes place; (b) women are faster learners that men; and (c) there is a persistency of overconfidence from one exam to the next, which is stronger for men. 


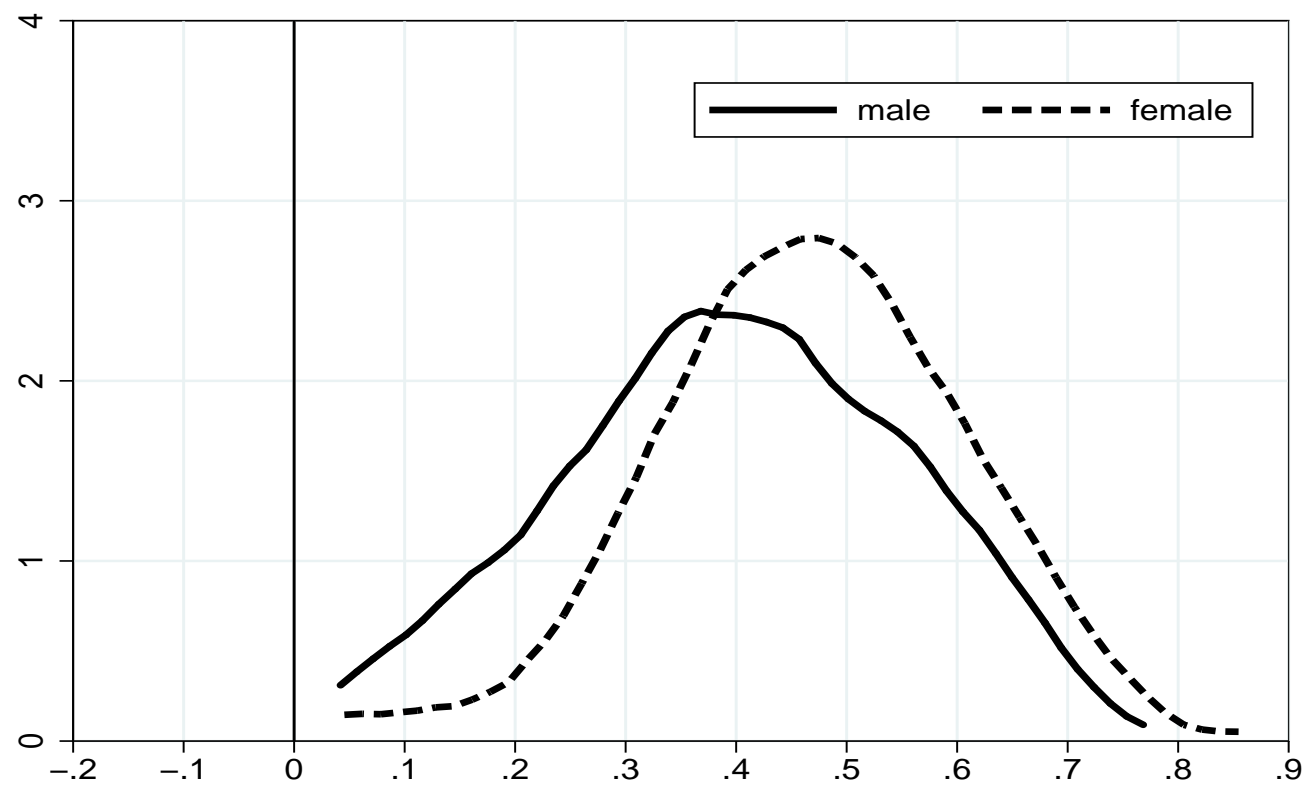

Figure 2: Persistence from exam 2 to exam 3 


\section{Conclusions}

In this paper we studied second-year undergraduate students in a statistics course over a period of five years, comparing their grades with their forecasts. As expected, we find that students' grade expectations are not rational and most of students are overconfident, which is in agreement with the general literature. Because of the relatively large number of students and the high response rate, our paper contributes to various issues (many unresolved) in the general area of rationality, overconfidence, and persistence. The following conclusions emerge.

First, overconfidence decreases during the course and is smallest at the third exam, which shows that students adjust their expectations as information accrues (Grimes, 2002; Burns, 2007), in particular when the third exam has a higher weight in the total course grade (Nowell and Alston, 2007). Some studies do not find this adjustment (Murstein, 1965; Serra and DeMarree, 2016; Foster et al., 2016), others do (Grimes, 2002; Burns, 2007). One of the reasons for the discrepancy in findings in the literature might be attributed to the content/essence/nature of the course. Foster et al. (2016) study the results of thirteen consecutive exams in educational psychology, where the content for each exam covers a separate topic. Our course is quite different in that the content is cumulative: the next exam uses concepts from previous parts of the course.

Second, female students have a lower level of overconfidence than male students, thus exhibiting more rational behavior. This is similar to what Guzman (2012) found in financial forecasts and Lundeberg et al. (1994) and Jakobsson (2012) for grade forecasts, while other researches do not find this difference (Maxwell and Lopus, 1994; Grimes, 2002; Andrews et al., 2007).

Third, female students are not only better forecasters, they are also faster learners than male students, showing faster adjustment of grade expectations.

Fourth, overconfidence has a positive effect on exam grades. Some studies suggest that overconfident students are less successful at exams since they allocate less time and efforts to study. In contrast, we find that overconfidence is advantageous, possibly because it increases ambitions, morale, resolve, persistence, and hence the probability of success (Ballard and Johnson, 2005; Johnson and Fowler, 2011).

\section{References}

Andrews, K., J. Swanson, and P. Kugler (2007). Grade expectations, Journal of Economics and Economic Education Research, 8, 3-18. 
Ballard, C., and M. Johnson (2005). Gender, expectations, and grades in introductory microeconomics at a US university, Feminist Economics, 11(1), 95-122.

Blackwell, C. (2010). Rational expectations in the classroom: A learning activity, Journal for Economic Educators, 10, 1-6.

Burns, D. J. (2007). An examination of the accuracy of students' expected grades, Academy of Educational Leadership Journal, 11, 45-58.

De Bondt, F. M., and R. H. Thaler (1995). Financial decision making in markets and firms: A behavioral perspective, In: Jarrow, R. A., V. Maksimovic, and W. T. Ziemba (Eds.) Handbooks in Operations Research and Management Science, Elsevier Science, Vol. 9, pp. 385410 .

Foster, N. L., C. A. Was, J. Dunlosky, and R. M. Isaacson (2016). Even after thirteen class exams, students are still overconfident: The role of memory for past exam performance in student predictions, Metacognition Learning. doi: 10.1007/s11409-016-9158-6 (in press).

Geide-Stevenson, D. (2009). Does collecting and grading homework assignments impact student achievement in an introductory economics course, Journal of Economics and Economic Education Research, 10, $3-14$.

Grimes, P. W. (2002). The overconfident principles of economics student: An examination of metacognitive skill, The Journal of Economic Education, 33, 15-30.

Guzman, G. (2012). Sexonomics: Gender, wealth, and expectations in financial markets, Journal of Economic and Social Measurement, 37(12). doi: 10.3233/JEM-2012-0357.

Hossain, B., and P. Tsigaris (2013). Can business students forecast their own grade?, American Journal of Business Education, 6, 85-91.

Hossain, B., and P. Tsigaris (2015). Are grade expectations rational? A classroom experiment, Education Economics, 23, 199-212.

Jakobsson, N. (2012). Gender and confidence: Are women underconfident?, Applied Economics Letters, 19, 1057-1059. 
Jensen, P. A., and R. Moore (2008). Students' behaviors, grades \& perceptions in an introductory biology course, The American Biology Teacher, $70,483-487$.

Johnson, D. D. P., and J. H. Fowler (2011). The evolution of overconfidence. Nature, 477(7364), 317-320. doi:10.1038/nature10384.

Khachikian, C. S., D. W. Guillaume, and T. K. Pham (2011). Changes in student effort and grade expectation in the course of a term, European Journal of Engineering Education, 36, 595-605.

Kruger, J., and D. Dunning (1999). Unskilled and unaware of it: How difficulties in recognizing one's own incompetence lead to inflated selfassessments, Journal of Personality and Social Psychology, 77, 11211134 .

Lundeberg, M. A., P. W. Fox, and J. Punccohar (1994). Highly confident but wrong: Gender differences and similarities in confidence judgments. Journal of Educational Psychology, 86, 114-121.

Maxwell N. L., and J. S. Lopus (1994). The Lake Wobegon effect in student self-reported data, The American Economic Review, 84, 201-205.

Murstein, B. I. (1965). The relationship of grade expectations and grades believed to be deserved to actual grades received, The Journal of Experimental Education, 33, 357-362.

Nowell, C., and R. M. Alston (2007). Thought I got an A! Overconfidence across the economics curriculum, The Journal of Economic Education, $38,131-142$

Serra, M. J., and K. G. DeMarree (2016). Unskilled and unaware in the classroom: College students' desired grades predict their biased grade predictions, Memory and Cognition, 44, 1127-1137. doi: 10.3758/s13421016-0624-9.

Sharma, V., and M. Shakeel (2015). Illusion versus reality: An empirical study of overconfidence and self attribution bias in business management students, Journal of Education for Business, 90, 199-207.

Sturges, D., T. W. Maurer, D. Allen, D. B. Gatch, and P. Shankar (2016). Academic performance in human anatomy and physiology classes: A 2-yr study of academic motivation and grade expectation, Advances in Physiology Education, 40, 26-31. doi:10.1152/advan.00091.2015. 
Svanum S., and S. Bigatti (2006). Grade expectations: Informed or uninformed optimism, or both?, Teaching of Psychology, 33, 14-18.

Svenson, O. (1981). Are we all less risky and more skillful than our fellow drivers?, Acta Psychologica, 47, 143-148.

Weems, G. (1998). The impact of homework collection in intermediate algebra, Research and Teaching in Developmental Education, 15, 2126 . 